\title{
Template-Directed Synthesis of Molecular
}

\section{Nanorings and Cages}

Pernille S. Bols and Harry L. Anderson*

Chemistry Research Laboratory, Department of Chemistry, Oxford University, Mansfield Road, Oxford OX1 3TA.

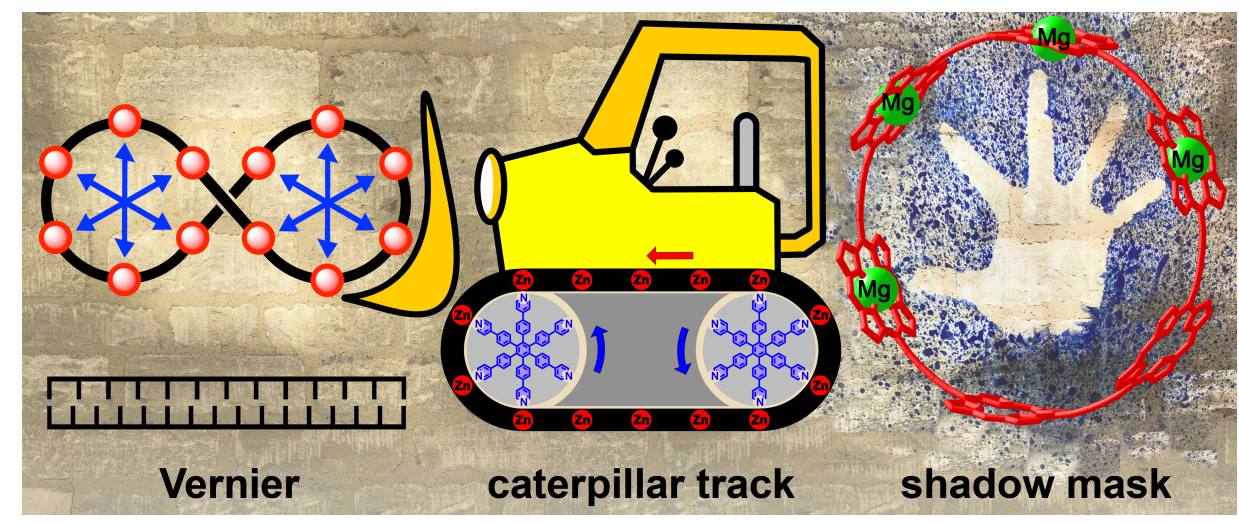

CONSPECTUS: This Account is about templates as construction tools: molecules for making molecules. A template organizes the reactants and provides information to promote formation of a specific product, but it is not part of the final product. We have developed many different strategies for using oligopyridines as templates for the synthesis of alkyne-linked $\pi$-conjugated metalloporphyrin oligomers. These compounds include some of the largest macrocycles ever synthesized, such as a 50-porphyrin ring with a diameter of $21 \mathrm{~nm}$ containing a ring of $750 \mathrm{C}-\mathrm{C}$ bonds. Metalloporphyrins are excellent models for exploring template directed synthesis, as they can be functionalized in many different positions and the central metal (typically $\mathrm{Zn}$ or $\mathrm{Mg}$ ) provides a handle for coordination to templates. 
Classical template-directed macrocyclization reactions have a 1:1 complementarity between the template and the product. This strategy works well for preparing nanorings of 5-7 porphyrin units, but larger templates are laborious to synthesize. Rings of 8 or more porphyrin units are most easily prepared using 'non-classical' strategies, in which several small templates work together to direct the formation of a large ring. In the Vernier approach, a mismatch between the number of binding sites on the template and the building block leads to a mathematical amplification of the length scale: the number of binding sites in the product is the lowest common multiple of those in the template and the building block. For example, a 40-porphyrin ring can be prepared by coupling a linear decamer in the presence of an octadentate template. Linear Vernier templating opens up intriguing possibilities for self-replication.

When several small radial oligopyridine templates bind inside a large nanoring they can form complexes with some vacant coordination sites that display correlated motion like the caterpillar tracks of a bulldozer. These caterpillar track complexes can be used in template-directed synthesis and they provide the most convenient route to 8 and 10-porphyrin rings. Russian doll complexes provide another strategy for template-directed synthesis: a number of specifically designed ligands bind to a central nanoring to form a template for constructing a larger concentric nanoring. The same oligopyridine templates that are used to prepare nanorings can also be used to synthesize three-dimensional nanotubes and nanoballs. Again, non-classical approaches, in which several small templates work together cooperatively, are much simpler than creating a single large template with sufficient binding sites to define the whole geometry of the product.

Oligopyridine ligands can also be used as shadow mask templates to control the demetallation of magnesium porphyrin nanorings, because metal centers that are not coordinated by the template can be selectively demetallated with acid. Thus the template forms a permanent shadow on the porphyrin nanostructure that remains after the template has been removed. Shadow mask templates provide a simple route to heterometallated molecular architectures. The insights 
emerging from these studies are widely applicable, and there are many opportunities for inventing new ways of using templates to control reactions.

\section{INTRODUCTION}

The word 'template' is used in many different ways. We start this Account by explaining our definition. To put it simply, we have in mind the wooden frames that builders use to hold stone blocks in place while they are cemented together to form an arch (Figure 1). The template defines the shape of the arch but it is not part of the final building.

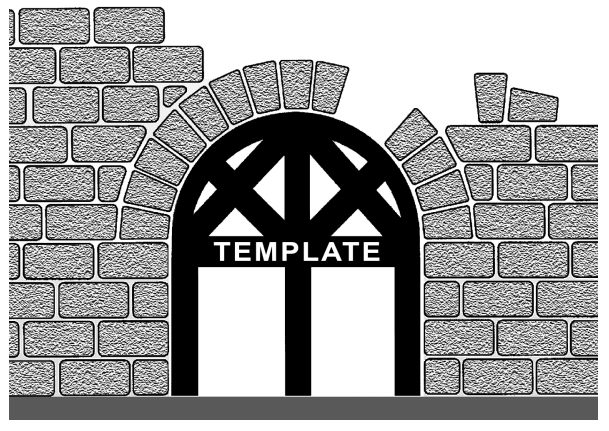

Figure 1. A template holds stones in place while they are cemented together to form an arch, then it is removed from the final structure.

Busch provided a formal definition,

"A chemical template organizes an assembly of atoms, with respect to one or more geometric loci, in order to achieve a particular linking of atoms. " 1

which was refined by Sanders: 
"The template provides instructions for the formation of a single product from a substrate or substrates which otherwise have the potential to assemble and react in a variety of ways." 2

In most cases, templates are not catalysts and a stoichiometric amount of template is required to form the product. However, at least in principle, the template can be removed from the product, which means that the template must connect to the substrate or substrates via temporary bonding interactions. These temporary interactions are often metal-ligand coordination bonds, but they can also be H-bonds, van der Waals interactions, or cleavable covalent bonds. The first chemical templates were metal cations, and metal cation templates continue to be used to create spectacular new architectures, such as rotaxanes, catenanes and knots. ${ }^{3-6}$ Metal cation templates are typically used with building blocks that are amine or ether ligands. In the template-directed synthesis of porphyrin arrays, the roles are reversed: the metal cation is part of the building block and the template is a multi-dentate amine ligand. ${ }^{2,7-11}$ Anions also find increasing use as templates, via H-bonding interactions. ${ }^{12,13}$ For example, Kobayashi and coworkers prepared a cyclo[10]pyrrole using croconate $\left(\mathrm{C}_{5} \mathrm{O}_{5}{ }^{2-}\right)$ as a template, ${ }^{14}$ while the use of sulfate as a smaller template resulted in formation of the cyclo[8]pyrrole. Leigh's synthesis of a pentafoil knot uses both cationic and anionic templates $\left(\mathrm{Fe}^{2+}\right.$ and $\left.\mathrm{Cl}^{-}\right) .{ }^{5}$ Neutral H-bond acceptors, such as bis- $\mathrm{N}$ oxides, have also been used to synthesize capsules. ${ }^{15}$ Van der Waals interactions and aromatic stacking forces are less directional than metal-ligand bonds or H-bonds, which makes it difficult to predict how they will operate, but there are many cases where these soft interactions give rise to strong template effects. ${ }^{16,17}$ On the other hand, covalent bonds provide a predictable connection to the template, and ester links have been used in the template-directed synthesis of large macrocycles, rotaxanes and catenanes. ${ }^{18-21}$ 
Most examples of template-directed synthesis are under kinetic control: the template accelerates formation of the desired covalent architecture and the reaction is irreversible. If the reaction is reversible and under thermodynamic control, the template may favor formation of a specific product by binding it and shifting the equilibrium toward this species. The product can then be made kinetically stable by changing the conditions, so that the template can be removed without re-establishing the equilibrium. This field of dynamic combinatorial chemistry, which was pioneered by Sanders and Lehn during the $1990 \mathrm{~s},{ }^{22,23}$ is particularly open to serendipity. In a dynamic combinatorial library, simple building blocks are mixed together so that they can couple reversibly to form many possible species. Adding a template to this library can result in selective amplification of an unexpected product. For example, acetylcholine was found to template the formation of a hydrazone-linked catenane. This amazing result was neither designed nor anticipated. $^{24}$

Control of molecular topology has been an important area of template-directed synthesis ever since Sauvage discovered that metal cations can direct the formation of catenanes in $1983 .{ }^{6,25}$ In these systems, the metal template is 'passive': it dictates the topology of the coupling but it does not accelerate the coupling reaction. In 2006, Leigh and coworkers developed the concept of 'active metal templates'. ${ }^{26,27}$ These reactions use metal complexes of macrocyclic ligands in which the metal promotes coupling of two components to form a covalent thread through the cavity of the macrocycle. This strategy is 'traceless' in the sense that the newly formed thread does not need a recognition site for the metal, and in some cases the template can be used in substoichiometric amounts.

Self-replicators are a fascinating class of templates. ${ }^{28,29}$ In the simplest case, a self-replicator is a template for construction of another copy of itself. Alternatively, a self-replicator may be a 
template for a complementary structure, which in turn is a template for the original molecule, as in DNA replication. The challenge is to avoid the formation of stable template-template complexes, so as to achieve autocatalytic turnover and exponential growth. Designing an efficient self-replicator is more difficult than designing an effective template.

In this Account, we present some insights that were gained by studying the chemistry of porphyrin nanorings, $\boldsymbol{c}-\mathbf{P} \boldsymbol{N}$, of the type shown in Figure 2. The combination of metalloporphyrin building blocks and oligopyridine templates is a fruitful area for exploring new strategies for template-directed synthesis, because the template effect is directional and modular: one pyridine binding site coordinates to one metalloporphyrin center. This controllable directionality allows large porphyrin arrays to be created with high selectivity. ${ }^{2,7-11}$ The template effect can be tuned by changing the affinity of the metal for axial ligands and it can be expanded by using a metal that coordinates ligands on both faces. This work has generated porphyrin nanorings which are fascinating model systems for studying the delocalization of charge $\mathrm{e}^{30,31}$ and electronic excitation, ${ }^{32,33}$ and for mimicking photosynthetic light harvesting systems, but here we focus on their synthesis rather than on their physical properties.

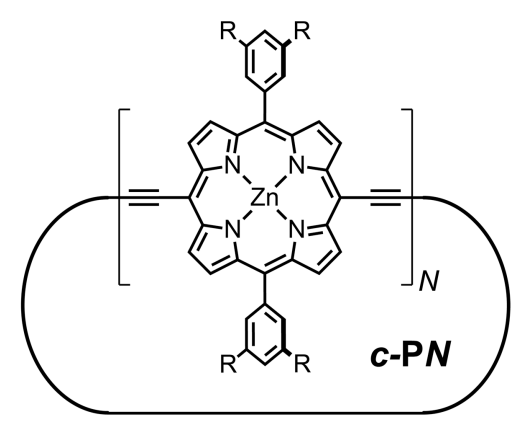

Figure 2. General structure of a porphyrin nanoring $\boldsymbol{c}-\mathbf{P} N$, $(c$ denotes $c y c l i c$, P: porphyrin, $N$ : number of porphyrins; $N=5-50$; the solubilizing group is $\mathrm{R}=t-\mathrm{Bu}, \mathrm{OC}_{8} \mathrm{H}_{17}$ or $\left.\mathrm{Si}\left(\mathrm{C}_{6} \mathrm{H}_{13}\right)_{3}\right)$. The corresponding linear oligomers are designated $\boldsymbol{l}$-PN, where $l$ denotes linear. 


\section{CLASSICAL TEMPLATE-DIRECTED MACROCYCLIZATION}

When we started thinking about the template-directed synthesis of $\pi$-conjugated cyclic porphyrin oligomers in 2005, it looked like a high-risk project. Although we and others had been working on linear $\pi$-conjugated porphyrin oligomers for more than 10 years, ${ }^{34-39}$ it was not clear that these molecules would be flexible enough to bend into rings, and we did not know whether we would be able to synthesize templates of just the right size to direct macrocyclization. The first breakthrough was the template-directed synthesis of a $\pi$-conjugated cyclic porphyrin octamer, $c$ P8. ${ }^{40}$ This was soon followed by a cyclic hexamer, $\boldsymbol{c - P 6}$ (Figure 3), ${ }^{41,42}$ which became the archetype for a family of nanorings. The rigid T6 template is almost the ideal size and shape for the cavity of $\boldsymbol{c - P 6}$; crystallographic studies indicate that it is $2.5 \%$ too small. ${ }^{42}$ It is effective as a template for forming $\mathbf{c - P 6}$ via the palladium-catalyzed oxidative homo-coupling of two linear porphyrin trimers, or three linear dimers, or six units of porphyrin monomer. The crystal structure of $\boldsymbol{c}$-P6· T6 shows that the molecule has a regular cylindrical $\pi$-system. ${ }^{42}$ This $\boldsymbol{c}$-P6 $\mathbf{T 6}$ complex is amazingly stable; it has a formation constant of about $10^{36} \mathrm{M}^{-1}$, due to the cooperative effect of six metal-template interactions with an effective molarity of about $300 \mathrm{M} .{ }^{43}$ However, the $\mathbf{T} \mathbf{6}$ template can be removed from the complex by displacement with a large excess of a competing ligand such as quinuclidine or DABCO, or by treating $\mathbf{c - P 6} \cdot \mathbf{T 6}$ with acid to remove the zinc atoms, to give the free-base nanoring, which can then be remetallated with zinc or another metal cation. 

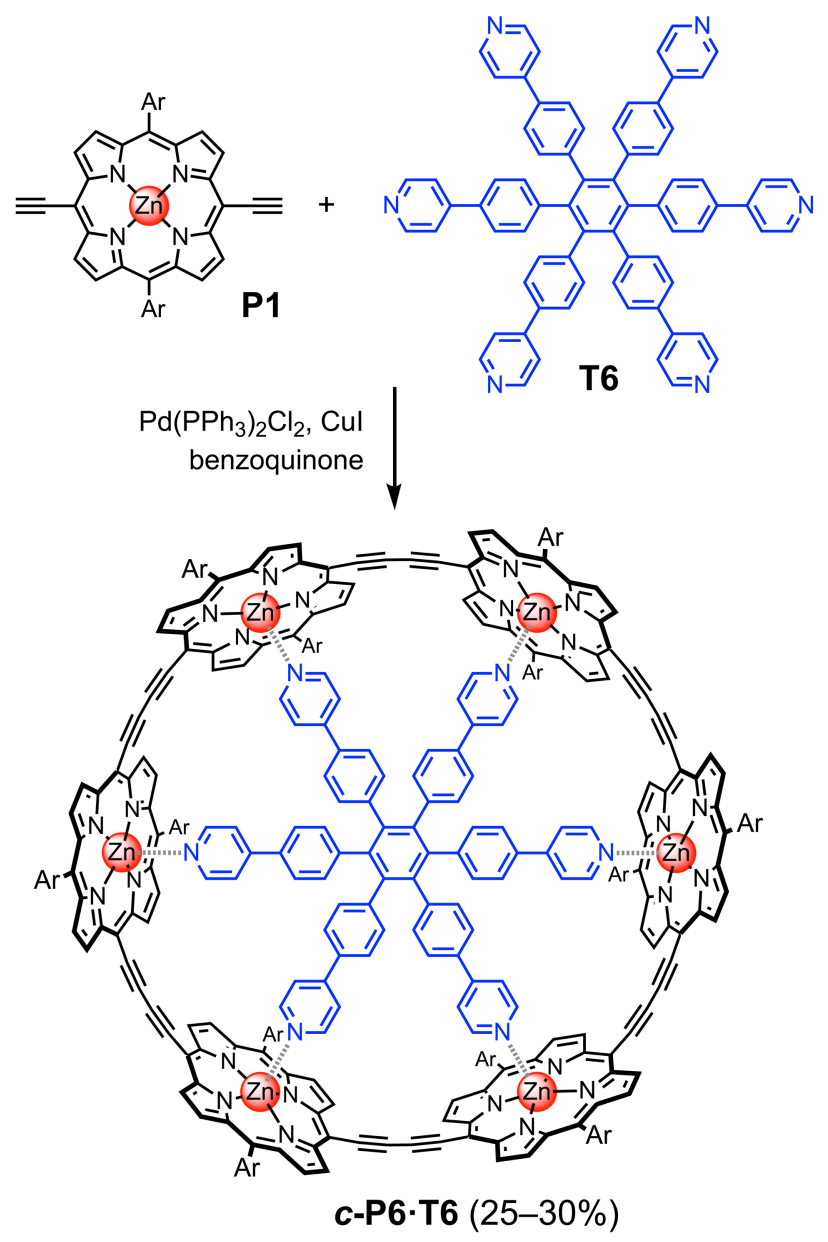

Figure 3. Template-directed synthesis of $\boldsymbol{c}$-P6. ${ }^{41,42}$

It might be imagined that the template-directed synthesis of $\mathbf{c - P 6}$ shown in Figure 3 involves the initial formation of a complex in which six porphyrin monomers bind to the T6 template, followed by intramolecular coupling. However this is unlikely to be the correct mechanism, because the strength of the zinc-nitrogen interaction under the reaction conditions is too weak to form a significant amount of the (P1) 6 T6 complex. Linear oligomers probably form by coupling of monomers that are not bound to the template; then they bind the template and couple further to form nanorings. 
The use of $\mathbf{T} 6$ to synthesize $\boldsymbol{c}-\mathbf{P 6}$ suggests that the template needs to be extremely rigid and to have a close geometrical match to the cavity of the target nanoring, however subsequent work showed that flexible or poorly matching templates can also be effective. For example, a flexible T7 template based on $\beta$-cyclodextrin was used to prepare $\boldsymbol{c}-\mathbf{P} 7$, in $4.7 \%$ yield from $\mathbf{P 1},{ }^{44}$ and a $\mathbf{T} 5$ template based on corannulene was used to synthesize $\boldsymbol{c}-\mathbf{P 5}$, in $6.1 \%$ yield from $\mathbf{P 1}$, even though the centroid-nitrogen distance of this template is calculated to be $11 \%$ too small for the cavity (Figure 4). ${ }^{45}$ The reason why flexible templates such as $\mathbf{T} 7$ are effective is probably that their complexes with linear porphyrin oligomers have well defined conformations, so that they can intercept these intermediates and facilitate ring closure by increasing the effective molarity for intramolecular cyclization. The largest template used in this type of reaction is T12, which yielded the 12-porphyrin ring $\boldsymbol{c}$-P12 by bringing together three equivalents of a linear porphyrin tetramer (Figure 4). ${ }^{46}$ Nearly all of the porphyrin oligomers discussed here are linked with butadiyne bridges, but recently we used Sonogashira coupling to prepare a six-porphyrin nanoring with single-acetylene links, $\boldsymbol{c}-\mathbf{P 6} \mathbf{}^{\prime}$, using the template $\mathbf{T 6}{ }^{\prime}{ }^{47}$ 


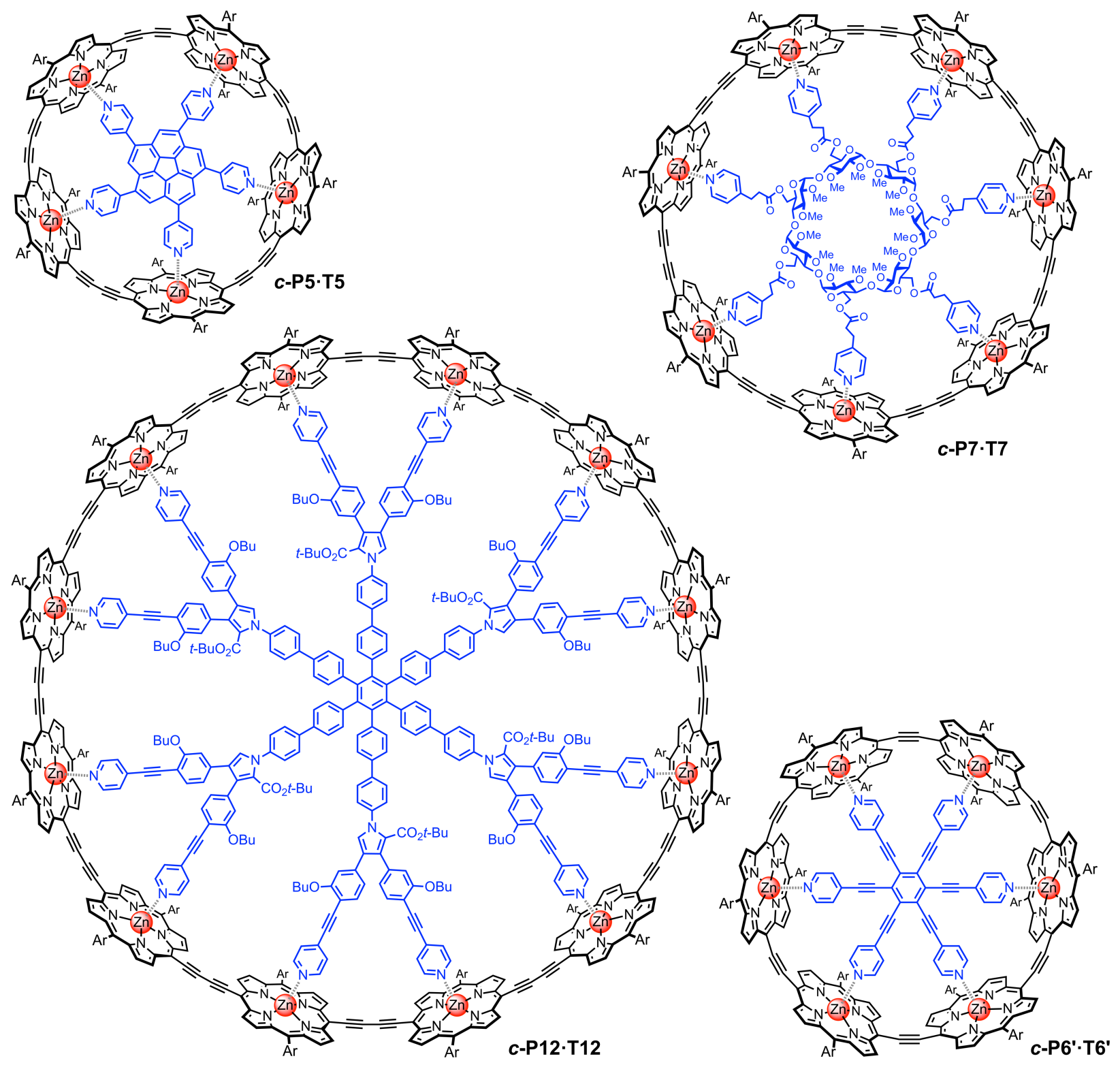

Figure 4. Nanoring-template complexes prepared via classical template-directed synthesis. ${ }^{44-47}$

\section{VERNIER TEMPLATES}

In the classical 1:1 template-directed reactions discussed above, a single template molecule defines the size of the product, and the product has the same number of binding sites as the template. The limitation of this strategy is that large macrocycles require large templates, which 
are difficult to synthesize. This problem prompted us to explore ways of using small templates to direct the formation of large nanorings. One solution is to use a Vernier complex.

Vernier complexes are formed when a host with $x$ binding sites binds a guest with $y$ binding sites, where $x$ is not a multiple of $y$. The Vernier complex has $z$ binding sites, where $z$ is the lowest common multiple of $x$ and $y$. The formation of a Vernier complex between components with different numbers of binding sites provides a way to amplify the molecular length-scale, generating precisely defined assemblies (Figure 5a). The name comes from the French mathematician Pierre Vernier (1580-1637) who applied this mismatch principle in measuring devices. The formation of supramolecular Vernier complexes was first suggested by Lindse ${ }^{48}$ by analogy with the self-assembly of collagen proteins. ${ }^{49}$ The principle has been applied to prepare double-strand ${ }^{50}$ and triple-strand ${ }^{51}$ non-covalent Vernier assemblies and dynamic covalent molecular ladders. ${ }^{52}$ Synthetic DNA nanostructures have also been created as Vernier complexes. ${ }^{53,54}$ We found that the formation of Vernier complexes is a powerful strategy for the template-directed synthesis of large macrocycles. ${ }^{46}$ The idea is based on the realization that Vernier complexes do not need to be linear (Figure 5b). A template with six binding sites, T6, binds to a building block with four binding sites, $l-\mathbf{P 4}$, to form a Vernier complex ( $\boldsymbol{l}$ P4) $)_{3} \cdot$ (T6) $)_{2}$, probably as two isomers. The $\boldsymbol{l}$-P4 units can then be coupled together covalently, to give a figure-of-eight complex, $\boldsymbol{c}$-P12·(T6) 2 in 39\% isolated yield (Figure 6). Displacement of the template with pyridine gives the free macrocycle $\boldsymbol{c}$-P12. The figure-of-eight geometry of $\boldsymbol{c}$ P12.(T6) 2 was deduced by NMR spectroscopy ${ }^{46}$ and confirmed by X-ray crystallography. ${ }^{55}$ 

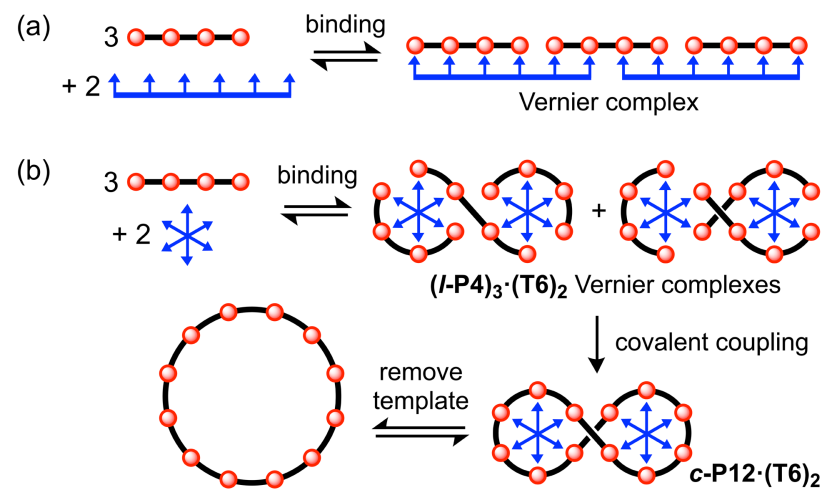

Figure 5. Cartoons showing the concept of Vernier templating. ${ }^{46,55}$ (a) Formation of a molecular 3:2 Vernier complex. (b) The use of Vernier complex formation to direct the formation of a 12site macrocycle (c-P12) using a 6-site template (T6).
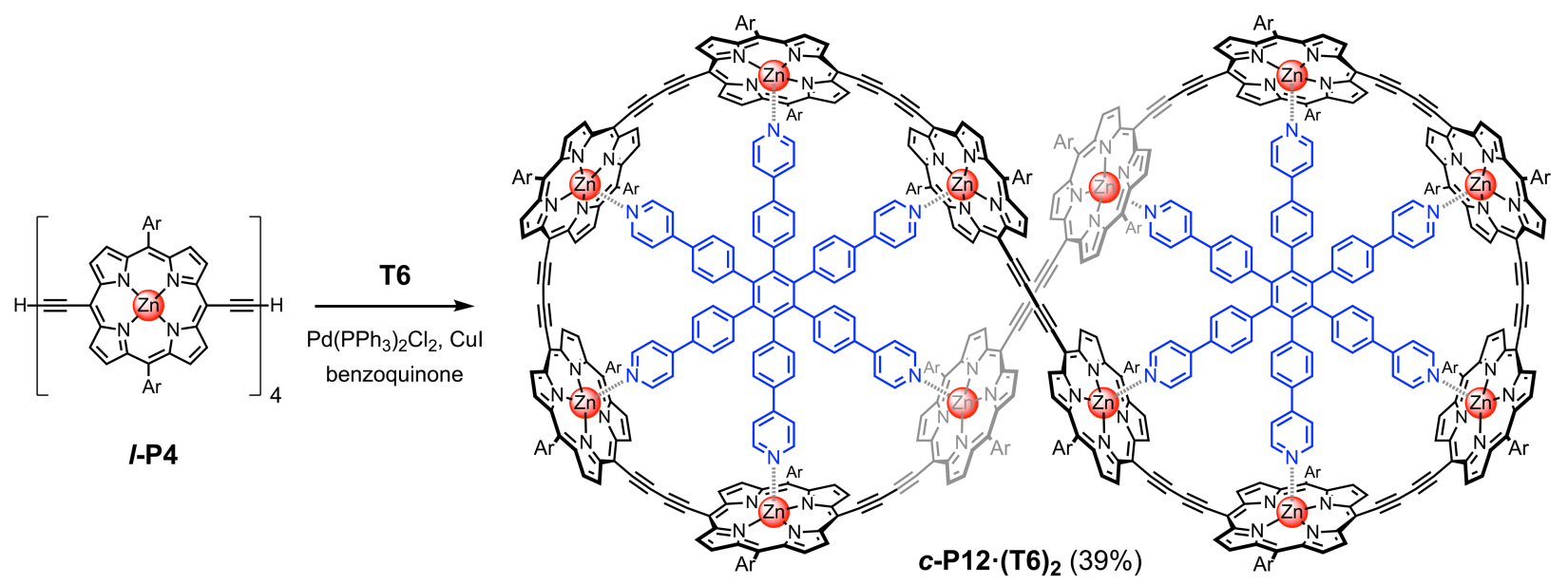

Figure 6. Vernier templated synthesis of $\boldsymbol{c}-\mathbf{P 1 2} .^{46,55}$ The isolated yield of $\boldsymbol{c}-\mathbf{P 1 2} \cdot(\mathbf{T 6})_{\mathbf{2}}$ is $39 \%$ for the case with $\mathrm{Ar}=3,5$-di-tert-butylphenyl.

Vernier templating has been used to prepare a range of large nanorings, including $\boldsymbol{c}-\mathbf{P 2 4}$ (both from $l$-P6 with T8 and from $\boldsymbol{l}$-P8 with T6), ${ }^{56} \boldsymbol{c}$-P30 (from $\boldsymbol{l}$-P10 with T6) and $\boldsymbol{c}$-P40 (from $\boldsymbol{l}$-P10 with T8). ${ }^{57}$ All these large nanorings were characterized by STM imaging on a gold surface with sufficient resolution to count the individual porphyrin units around the ring. For example Figure 7 shows images of $\boldsymbol{c}$-P24. ${ }^{56,58}$ The Vernier templated synthesis of these large nanorings is less 
selective than that of $\boldsymbol{c}$-P12, but all the different cyclic oligomers can be separated by recycling gel permeation chromatography, including products such as $\boldsymbol{c - P 5 0}$, which is the largest monodisperse covalent synthetic macrocycle yet reported. It is interesting that $\mathbf{c - P 5 0}$ is not formed by coupling $\boldsymbol{l}-\mathbf{P 1 0}$ in the absence of a template, but it is formed in $5-10 \%$ yield by running the reaction in the presence of either $\mathbf{T 6}$ or $\mathbf{T 8} .^{57}$
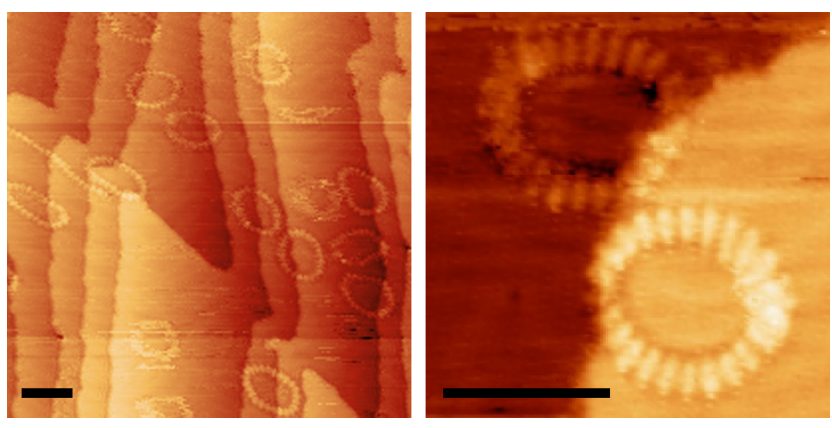

Figure 7. STM images of $\boldsymbol{c}-\mathbf{P 2 4}$ molecules on a gold surface. In both cases, the compound was deposited by electrospray from a solution in methanol/toluene containing $5 \%$ pyridine to prevent aggregation (scale bar $10 \mathrm{~nm}$; structure shown in Figure 2 with $\mathrm{R}=\mathrm{OC}_{8} \mathrm{H}_{17}$ ) ${ }^{56,58}$

The Vernier principle can also be applied to synthesize linear oligomers. Linear Vernier templating has some similarities with DNA replication, and it opens up the possibility of coupling along both strands of the Vernier complex, so that there is no distinction between the 'template' and the 'building block'. We have demonstrated this strategy, which we call 'mutual Vernier templating', in the synthesis of linear porphyrin dodecamers (Figure 8). ${ }^{59}$ In this design, a meso-4-pyridyl group was used to bind a nickel porphyrin strand to a zinc porphyrin strand. The nickel centers do not have significant affinity for pyridine ligands and they block accidental insertion of copper during the Glaser coupling reaction. The product duplex has reactive free 
alkyne terminals, which makes it necessary to limit the extent of coupling to avoid polymerization.

(a)

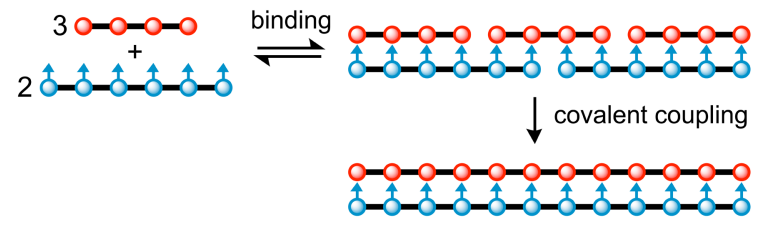

(b)

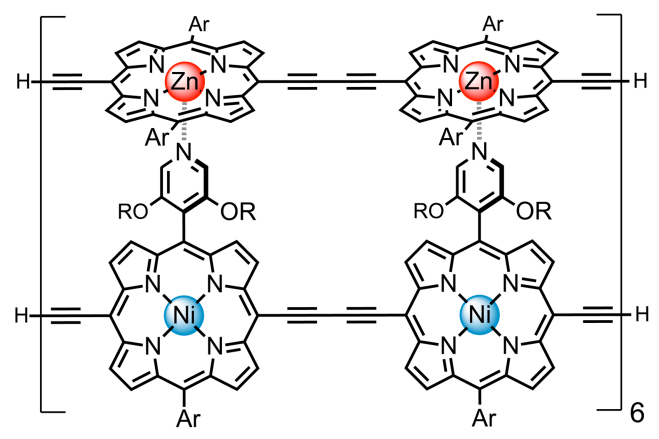

Figure 8. Mutual Vernier templating: both strands couple and there is no distinction between the 'template' and the 'substrate'. (a) Cartoon of the reaction; (b) structure of the product duplex. R $=\mathrm{C}_{12} \mathrm{H}_{25} ; \mathrm{Ar}=3,5$-bis(trihexylsilyl)phenyl. ${ }^{59}$

\section{CATERPILLAR TRACK TEMPLATES}

A mismatch between the number of binding sites on a host and guest does not always lead to a Vernier complex - it can also give complexes with vacant coordination sites. For example, when $\mathbf{T 6}$ is added to $\boldsymbol{c - P 1 0}$ the product is a 2:1 complex, $\boldsymbol{c - P 1 0} \cdot(\mathbf{T 6})_{2}$. Similarly, addition of $\mathbf{T 6}$ to $\boldsymbol{c}$-P8 forms $\boldsymbol{c}$-P8·(T6) 2 (Figure 9). ${ }^{60}{ }^{1} \mathrm{H}$ NMR exchange spectroscopy experiments (EXSY) show that these complexes are dynamic in solution and that the two template units rotate in a correlated way, like the caterpillar tracks of a bulldozer. This correlated motion resembles that in a molecular gear, except that in caterpillar track complexes the rotation of the two template "wheels" is conrotatory, whereas in a gear the motion is disrotatory. If some of the pyridine sites 
on the template are deleted, similar "caterpillar track" complexes can be formed which have no vacant coordination sites and which are not dynamic. The formation of these complexes can be exploited for template-directed synthesis; for example, coupling the linear porphyrin dimer $\boldsymbol{l}$-P2 in the presence of $\mathbf{T} 4$ or $\mathbf{T 5}$ gives $\boldsymbol{c}$-P8 or $\boldsymbol{c}$-P10, respectively (Figure 10). ${ }^{60}$ This strategy was used recently to prepare a 8-porphyrin nanoring with single-acetylene links. ${ }^{47}$ The two main advantages of caterpillar templating, compared with classical 1:1 templating, are that smaller templates are easier to synthesize, and that the size and shape of the template do not need to be so well matched to the cavity of the target structure. The synthesis of $c$-P50 from $\boldsymbol{l}$-P10 using T6 or $\mathbf{T 8}$ as templates, mentioned above, probably involves intermediates similar to caterpillar track complexes with some vacant coordination sites (uncoordinated template nitrogens or zinc centers). The $\boldsymbol{l}$-P50 intermediate must bind several template units in such a way as to bend it into a cyclic conformation with a high effective molarity between the terminal alkynes.

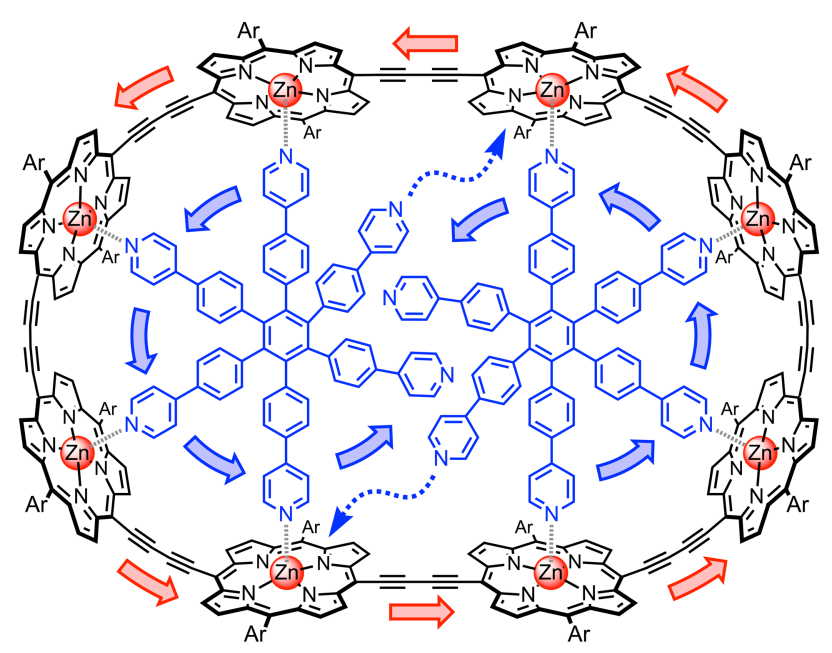

Figure 9. Caterpillar track motion in $\boldsymbol{c}$-P8·(T6) $)_{2}$, as revealed by ${ }^{1} \mathrm{H}$ NMR EXSY experiments. ${ }^{60}$ The red and blue arrows show the directions of motion of the porphyrin and template units, respectively, and the dashed arrows indicate how ligand sites coordinate to zinc centers. 


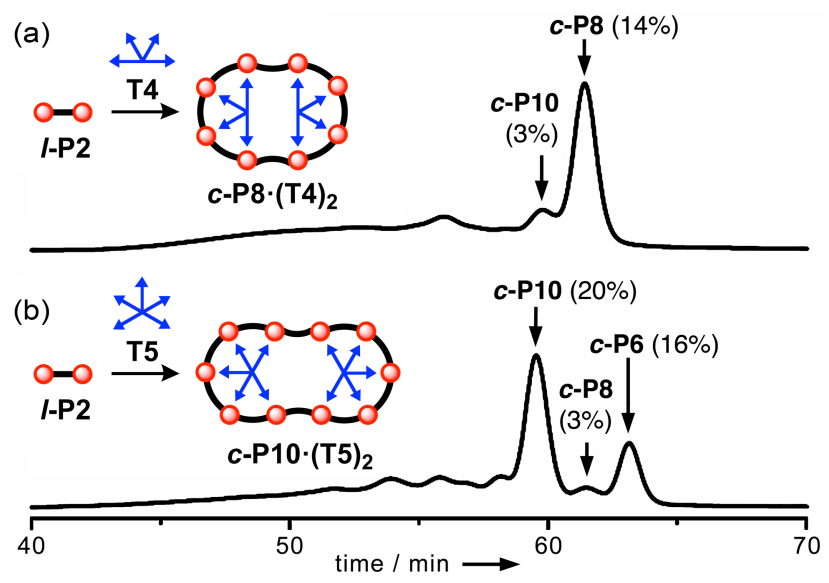

Figure 10. Caterpillar track templating. Cartoons showing coupling of a porphyrin dimer (l-P2) in the presence of templates (a) T4 and (b) T5, together with analytical GPC traces of the crude reaction mixtures from these three reactions. ${ }^{60}$

\section{RUSSIAN DOLL TEMPLATING}

Hierarchical ring-in-ring assemblies suggest that larger and larger molecules might be created by building shells out from a central core, such that each shell acts as a template for the next. We explored this idea by investigating a Russian doll complex consisting of an aluminum $\boldsymbol{c}$-P6 held inside zinc $\boldsymbol{c - P 1 2}$ by six bis-imidazole-carboxylate ligands (Figure 11). ${ }^{61}$ Aluminum is used for the inside ring because it coordinates two axial ligands: an anionic ligand, such as carboxylate, at one face and a neutral ligand, such as pyridine, at the other face. The complex of aluminum $\boldsymbol{c - P 6}$ and the bis-imidazole-carboxylate ligands is an effective template for directing the formation of the outer $\boldsymbol{c}$-P12 ring from linear tetramer $\mathbf{l - P 4}$. However, it would not be simple to extend this approach to even larger structures. 


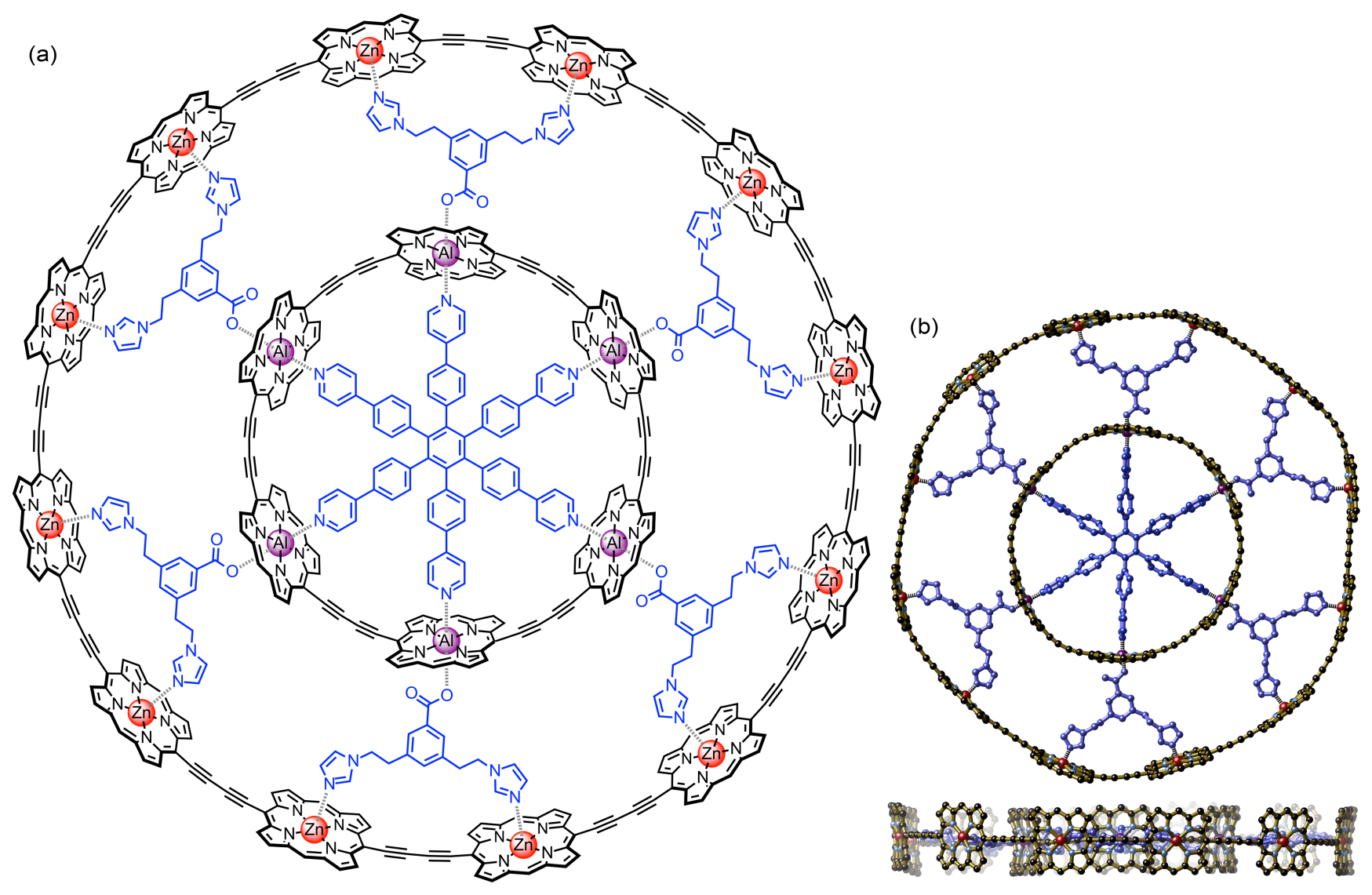

Figure 11. Structure of the Russian doll complex. ${ }^{61}$ (a) Chemical structure (with meso-aryl side groups omitted for clarity). (b) Two orthogonal views of the calculated structure (meso-aryl side groups were not included in the calculations; hydrogen atoms omitted for clarity).

\section{TUBES AND BALLS}

The discussion above (Sections 2-5) focused on using templates to create topologically flat cyclic porphyrin oligomers. Similar strategies can be used to create 3D tubes and cages, by starting from slightly more elaborate building blocks, as illustrated by the architectures in Figure 12. ${ }^{62-64}$ All three of these structures were synthesized using the same $\mathbf{T 6}$ template (introduced in Figure 3). Two units of $\mathbf{T 6}$ were used to direct the synthesis of the 12-porphyrin nanotube (Figure 12a) ${ }^{62}$ and the 11-porphyrin spiro-structure (Figure 12b). ${ }^{63}$ The 14-porphyrin ball (Figure 
$12 \mathrm{c})^{64}$ was prepared by first using the $\mathbf{T} \mathbf{6}$ template to convert two porphyrin trimers into a cyclic hexamer, then coupling four equivalents of a linear dimer to this 6-porphyrin nanoring, then using two equivalents of a $\mathbf{T 4}$ template to create an orthogonal 10-porphyrin nanoring; finally both the $\mathbf{T} 6$ and $\mathbf{T} 4$ templates were removed by treatment with excess pyridine (Figure 13).

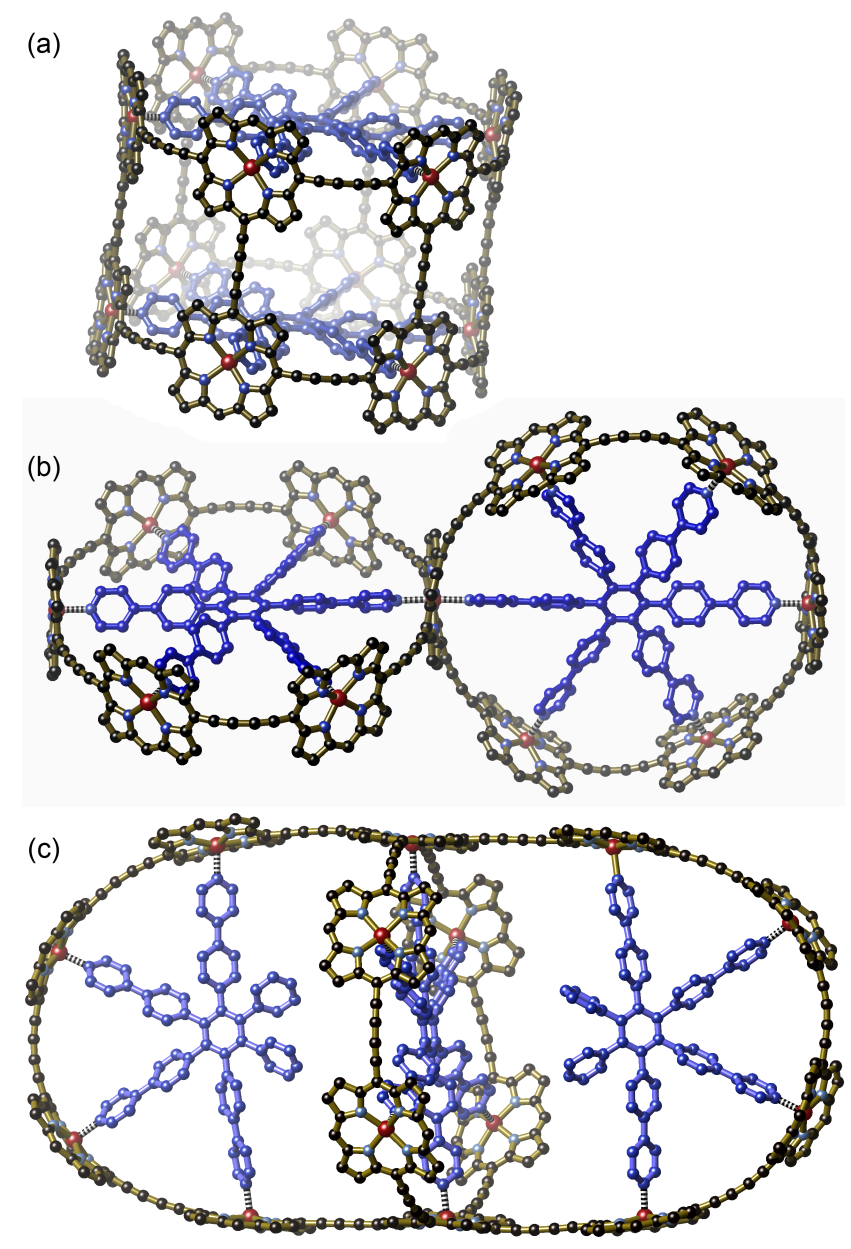

Figure 12. Calculated geometries of (a) a 12-porphyrin nanotube bound to two T6 templates, ${ }^{62}$ (b) an 11-porphyrin spiro-structure bound to two $\mathbf{T 6}$ templates, ${ }^{63}$ and (c) a 14-porphyrin nanoball bound to a $\mathbf{T 6}$ template and two $\mathbf{T} 4$ templates. $^{64}$ 


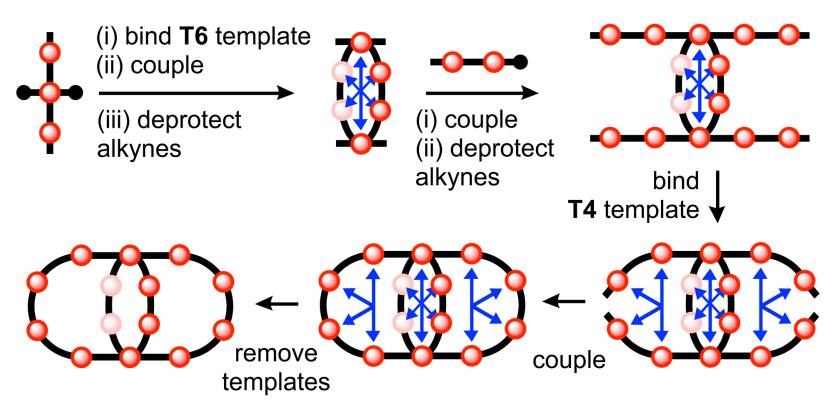

Figure 13. A simplified representation of the template-directed synthesis of a 14-porphyrin nanoball. ${ }^{64}$ (Red spheres represent zinc porphyrins; black lines and circles represent acetylene bridges and protecting groups, respectively.)

\section{SHADOW MASK TEMPLATES}

Recently, we discovered a new type of template effect through studying magnesium porphyrin nanorings. ${ }^{65}$ Oligopyridine templates can be used as masks to protect specific sites from demetallation when a magnesium porphyrin nanoring is treated with acid (Figure 14). Magnesium cations are easily removed from a porphyrin by weak acid, but if the magnesium is coordinated to an axial pyridine ligand, demetallation is prevented. We prepared the magnesium six-porphyrin nanoring $\mathbf{M g} \mathbf{g}_{\mathbf{6}} \mathbf{c - P 6}$ and inserted oligopyridine templates with five, four and three legs in specific positions. When these complexes are treated with acetic acid in dichloromethane, the uncoordinated magnesium cations are removed, and the coordinated magnesium cations remain in place. Interestingly, the template is bound strongly enough to the host so that it is not protonated and removed by the weak acid. After site-selective demetallation, the templates can be removed using a competing ligand, such as DABCO. For the five- and four-legged templates, the selective demetallation proceeds quantitatively without any side products. With the threelegged templates, the completely demetallated nanoring $\left(\mathbf{H}_{2}\right)_{\mathbf{6}}-\mathbf{c - P 6}$ is formed as a minor byproduct, resulting in moderate yields $(56-83 \%)$ of product. We attribute this side reaction to 
the weaker binding constants of three legged templates. ${ }^{43}$ Using this method, we prepared two heterometallated nanorings, one with two paramagnetic copper(II) ions and one with two zinc(II) ions (Figure 15).
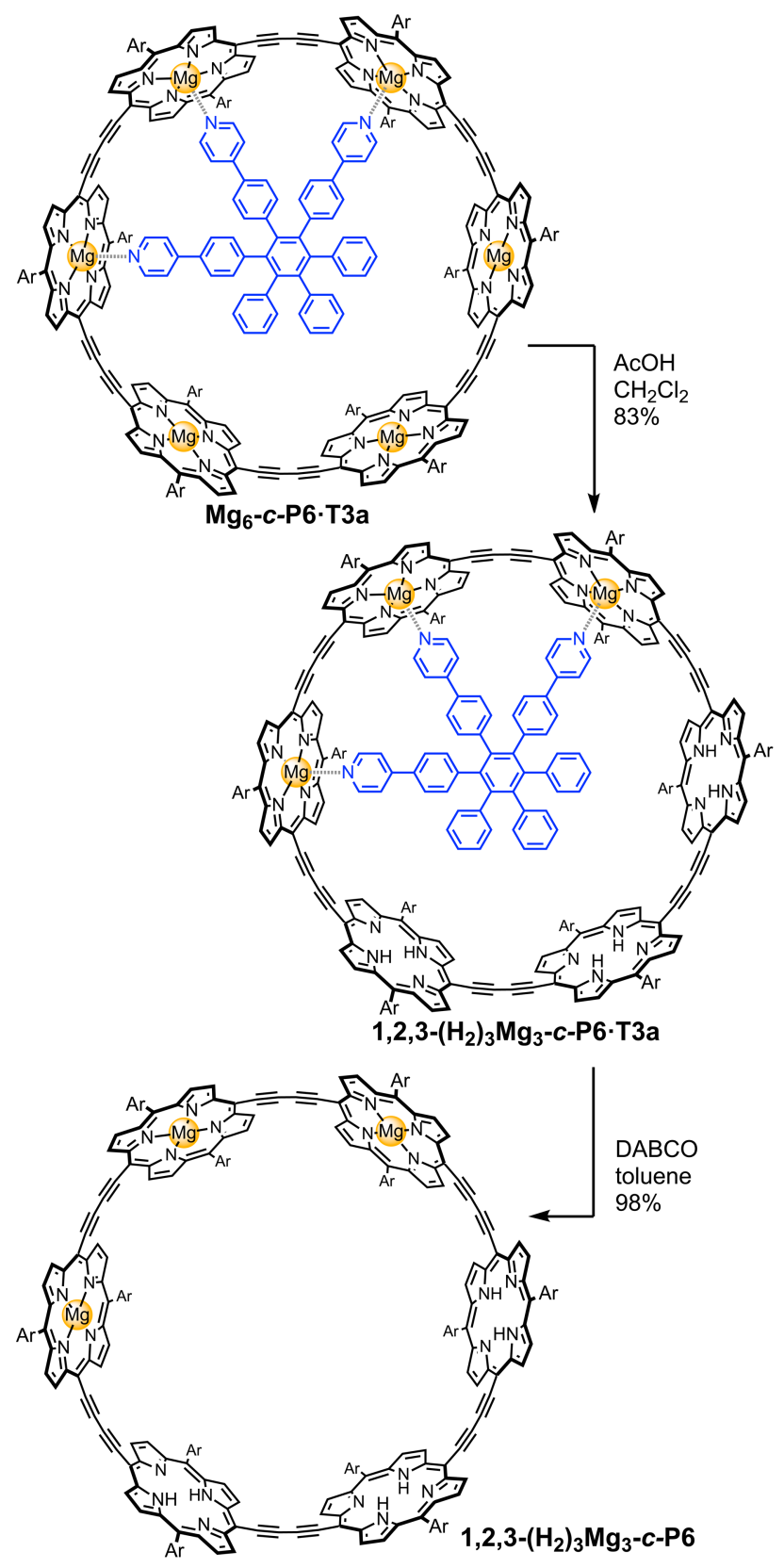

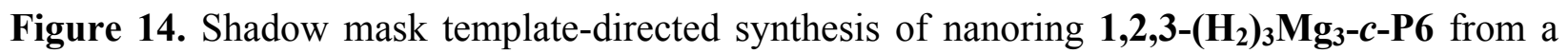
hexamagnesium nanoring masked by the template T3a. $\mathrm{Ar}=3,5$-bis(trihexylsilyl)phenyl. ${ }^{65}$ 


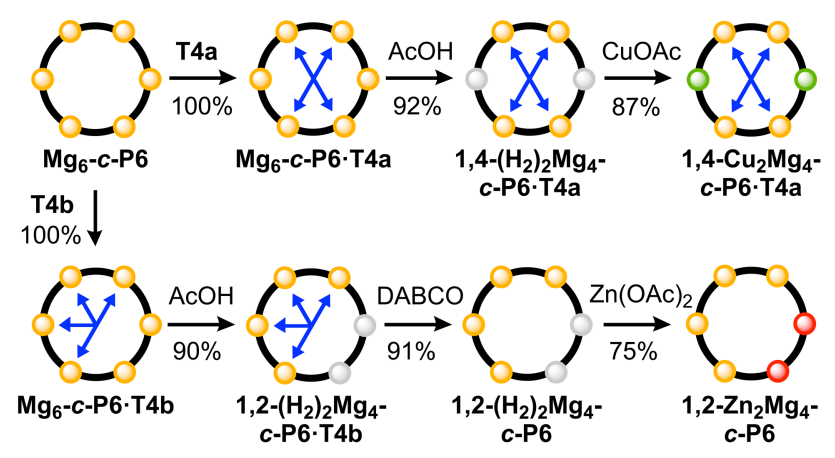

Figure 15. Shadow mask templates applied to the synthesis of $\mathbf{1 , 4}-\mathbf{C u}_{2} \mathbf{M g}_{4}-\boldsymbol{c}-\mathbf{P 6} \cdot \mathbf{T} 4 \mathrm{a}$ and $\mathbf{1 , 2}-$ $\mathbf{Z n}_{2} \mathbf{M g}_{4}-\boldsymbol{c}$-P6 using the templates $\mathbf{T 4 a}$ and $\mathbf{T} 4 \mathbf{b}$ respectively followed by insertion of copper(II) and zinc(II). ${ }^{65}$

\section{CONCLUSIONS AND OUTLOOK}

Oligopyridine ligands are tremendously versatile templates for synthesizing metalloporphyrin cages, and they provide access to many molecular architectures which would otherwise be unobtainable. ${ }^{11}$ This work illustrates the diversity of template effects; for example, a shadow mask template operates in a very different way from a classical macrocyclization template. Yet another mode of operation is illustrated by scavenger templates, which promote formation of a given product by scavenging a species which would otherwise interfere with the desired reaction. ${ }^{66,67}$

A recurring theme in this work is the use of several molecules of the same template, which work together cooperatively to direct the formation of a larger structure. It is easier to build a large porphyrin nanoring by using several small template units to form a Vernier complex, or a caterpillar track complex, or a Russian doll complex, rather than using a single large template. Similarly in the synthesis of the 14-porphyrin nanoball (Figures 12c and 13), we found it easier to use one $\mathbf{T 6}$ template and two $\mathbf{T} 4$ templates to define the cavity of the cage, rather than using a 
bespoke 14-site template. The principle of using multiple templates in the same transformation also applies to work on metal cation templates. ${ }^{3,5}$ There are still many challenges in this field; for example, we have not yet devised a way to use oligopyridine templates to create catenanes or knots (other than the use of a simple copper active metal template) ${ }^{68}$ and we have just started to gain access to 3D ball-shaped geometries. Linear template-directed synthesis and mutual Vernier templating open up many possibilities for creating information-rich self-replicators. It would also be fascinating to take these systems into thermodynamic control and generate dynamic combinatorial libraries of $\pi$-conjugated porphyrin arrays, and this might be possible if better catalysts can be developed for alkyne metathesis. ${ }^{69,70}$

\section{AUTHOR INFORMATION}

\section{Corresponding Author}

*E-mail: harry.anderson@chem.ox.ac.uk

\section{ORCID}

Harry L. Anderson: 0000-0002-1801-8132

Pernille S. Bols: 0000-0002-5749-7172

\section{Biographical Information}

Pernille S. Bols graduated with a Masters in Chemistry from the University of Copenhagen in 2017. She is now studying for a DPhil at Oxford University on the synthesis and properties of heterometallated porphyrin arrays and quantum interference effects in nanorings. 
Harry L. Anderson completed his PhD with Jeremy K. M. Sanders at the University of Cambridge and pursued postdoctoral work with François Diederich at ETH Zurich, Switzerland. He has led an independent research group at the University of Oxford since 1995.

\section{Notes}

The authors declare no competing financial interest.

\section{ACKNOWLEDGMENT}

We thank the EPSRC, the ERC (grant 320969) and the John Templeton Foundation for generous support. The following members of the group made major contributions to the advances summarized in this Account: Craig J. Wilson, Markus Hoffmann, Johannes K. Sprafke, Dmitry V. Kondratuk, Melanie C. O'Sullivan, Patrik Neuhaus, Arjen Cnossen, Ludovic Favereau, Sophie A. L. Rousseaux, Nuntaporn Kamonsutthipaijit, Jonathan Cremers, Renée Haver, Michel Rickhaus and Lara Tejerina.

\section{ABBREVIATIONS}

DABCO, 1,4-diazabicyclo[2.2.2]octane; EXSY, exchange spectroscopy; GPC, gel permeation chromatography, STM, scanning tunneling microscopy.

\section{REFERENCES}

1) Busch, D. H. Structural Definition of Chemical Templates and the Prediction of New and Unusual Materials. J. Inclusion Phenom. Macrocyclic Chem. 1992, 12, 389-395.

2) Anderson, S.; Anderson, H. L.; Sanders, J. K. M. Expanding Roles for Templates in Synthesis. Acc. Chem. Res. 1993, 26, 469-475. 
3) Pentecost, C. D.; Chichak, K. S.; Peters, A. J.; Cave, G. W. V.; Cantrill, S. J.; Stoddart, J. F. A Molecular Solomon Link. Angew. Chem. Int. Ed. 2007, 46, 218-222.

4) Guo, J.; Mayers, P. C.; Breault, G. A.; Hunter, C. A. Synthesis of a Molecular Trefoil Knot by Folding and Closing on an Octahedral Coordination Template. Nat. Chem. 2010, 2, 218-222.

5) Marcos, V.; Stephens, A. J.; Jaramillo-Garcia, J.; Nussbaumer, A. L.; Woltering, S. L.; Valero, A.; Lemonnier, J. F.; Vitorica-Yrezabal, I. J.; Leigh, D. A. Allosteric Initiation and Regulation of Catalysis with a Molecular Knot. Science 2016, 352, 1555-1559.

6) Chambron, J.-C.; Sauvage, J.-P. Topologically Complex Molecules Obtained by Transition Metal Templation: It is the Presentation that Determines the Synthesis Strategy. New J. Chem. 2013, 37, 49-57.

7) Anderson, H. L.; Sanders, J. K. M. Amine-Template Directed Synthesis of Cyclic Porphyrin Oligomers. Angew. Chem. Int. Ed. Engl. 1990, 29, 1400-1403.

8) Yu, L.; Lindsey, J. S. Rational Syntheses of Cyclic Hexameric Porphyrin Arrays for Studies of Self-Assembling Light-Harvesting Systems. J. Org. Chem. 2001, 66, 7402-7419.

9) Rucareanu, S.; Schuwey, A.; Gossauer, A. One-Step Template-Directed Synthesis of a Macrocyclic Tetraarylporphyrin Hexamer Based on Supramolecular Interactions with a $C_{3}$ Symmetric Tetraarylporphyrin Trimer. J. Am. Chem. Soc. 2006, 128, 3396-3413.

10) Zhu, B.; Chen, H.; Lin, W.; Ye, Y.; Wu, J.; Li, S. Template-Directed Synthesis of Flexible Porphyrin Nanocage and Nanorings via One-Step Olefin Metathesis. J. Am. Chem. Soc. 2014, $136,15126-15129$. 
11) Wang, S.-P.; Shen, Y.-F.; Zhu, B.-Y.; Wu, J.; Li, S. Recent Advances in the TemplateDirected Synthesis of Porphyrin Nanorings. Chem. Commun. 2016, 52, 10205-10216.

12) Spence, G. T.; Beer, P. D. Expanding the Scope of the Anion Templated Synthesis of Interlocked Structures. Acc. Chem. Res. 2013, 46, 571-586.

13) Lisbjerg, M.; Jessen, B. M.; Rasmussen, B.; Nielsen, B. E.; Madsen, A. Ø.; Pittelkow, M. Discovery of a Cyclic $6+6$ Hexamer of D-Biotin and Formaldehyde. Chem. Sci. 2014, 5, $2647-$ 2650.

14) Okujima, T.; Ando, C.; Agrawal, S.; Matsumoto, H.; Mori, S.; Ohara, K.; Hisaki, I.;

Nakae, T.; Takase, M.; Uno, H.; Kobayashi N. Template Synthesis of Decaphyrin without MesoBridges: Cyclo[10]pyrrole. J. Am. Chem. Soc. 2016, 138, 7540-7543.

15) Galán, A.; Escudero-Adán, E. C.; Ballester, P. Template-Directed Self-Assembly of Dynamic Covalent Capsules with Polar Interiors. Chem. Sci. 2017, 8, 7746-7750.

16) Dale, E. J.; Vermeulen, N. A.; Thomas, A. A.; Barnes, J. C.; Juríček, M.; Blackburn, A. K.; Strutt, N. L.; Sarjeant, A. A.; Stern, C. L.; Denmark, S. E.; Stoddart, J. F. ExCage. J. Am. Chem. Soc. 2014, 136, 10669-10682.

17) Ogoshi, T.; Ueshima, N.; Akutsu, T.; Yamafuji, D.; Furuta, T.; Sakakibara, F.; Yamagishi, T. The Template Effect of Solvents on High Yield Synthesis, Co-cyclization of Pillar[6]arenes and Interconversion between Pillar[5]- and Pillar[6]arenes. Chem. Commun. 2014, 50, 5774 5777. 
18) Höger, S.; Meckenstock, A.-D.; Pellen, H. High-Yield Macrocyclization via Glaser Coupling of Temporary Covalent Templated Bisacetylenes. J. Org. Chem. 1997, 62, 4556-4557.

19) Godt, A. Non-Rusty [2]Catenanes with Huge Rings and Their Polymers. Eur. J. Org. Chem. 2004, 1639-1654.

20) Jung, S.-H.; Pisula, W.; Rouhanipour, A.; Räder, H. J.; Jacob, J.; Müllen, K. A Conjugated Polycarbazole Ring Around a Porphyrin. Angew. Chem. Int. Ed. 2006, 45, 4685-4690.

21) Schweez, C.; Shushkov, P.; Grimme, S.; Höger, S. Synthesis and Dynamics of Nanosized Phenylene-Ethynylene-Butadiynylene Rotaxanes and the Role of Shape Persistence, Angew. Chem. Int. Ed. 2016, 55, 3328-3333.

22) Corbett, P. T.; Leclaire, J.; Vial, L.; West, K. R.; Wietor, J.-L.; Sanders, J. K. M.; Otto, S. Dynamic Combinatorial Chemistry. Chem. Rev. 2006, 106, 3652-3711.

23) Lehn, J.-M. Dynamic Combinatorial Chemistry and Virtual Combinatorial Libraries. Chem. Eur. J. 1999, 5, 2455-2463.

24) Lam, R. S. T.; Belenguer, A.; Roberts, S. L.; Naumann, C.; Jarrosson, T.; Otto, S.; Sanders, J. K. M. Amplification of Acetylcholine-Binding Catenanes from Dynamic Combinatorial Libraries. Science 2005, 308, 667-669.

25) Dietrich-Buchecker, C. O.; Sauvage, J. P.; Kintzinger, J. P. Une Nouvelle Famille de Molecules: Les Metallo-Catenanes. Tetrahedron Lett. 1983, 24, 5095-5098. 
26) Aucagne, V.; Hänni, K. D.; Leigh, D. A.; Lusby, P. J.; Walker, D. B. Catalytic "Click” Rotaxanes: A Substoichiometric Metal-Template Pathway to Mechanically Interlocked Architectures. J. Am. Chem. Soc. 2006, 128, 2186-2187.

27) Crowley, J. D.; Goldup, S. M.; Lee, A.-L.; Leigh, D. A.; McBurney, R. T. Active Metal Template Synthesis of Rotaxanes, Catenanes and Molecular Shuttles. Chem. Soc. Rev. 2009, 38, $1530-1541$.

28) Wintner, E. A.; Conn, M. M.; Rebek, J., Jr. Studies in Molecular Replication. Acc. Chem. Res. 1994, 27, 198-203.

29) Robertson, A.; Sinclair, A. J.; Philp, D. Minimal Self-Replicating Systems. Chem. Soc. Rev. 2000, 29, 141-152.

30) Peeks, M. D.; Claridge, T. D. W.; Anderson, H. L. Aromatic and Antiaromatic Ring Currents in a Molecular Nanoring. Nature 2017, 541, 200-203.

31) Peeks, M. D.; Tait, C. E.; Neuhaus, P.; Fischer, G. M.; Hoffmann, M.; Haver, R.; Cnossen, A.; Harmer, J. R.; Timmel, C. R.; Anderson, H. L. Electronic Delocalization in the Radical Cations of Porphyrin Oligomer Molecular Wires. J. Am. Chem. Soc. 2017, 139, 10461-10471.

32) Parkinson, P.; Kondratuk, D. V.; Menelaou, C.; Gong, J. Q.; Anderson, H. L.; Herz, L. M. Chromophores in Molecular Nanorings - When is a Ring a Ring? J. Phys. Chem. Lett. 2014, 5, $4356-4361$.

33) Yong, C. K.; Parkinson, P.; Kondratuk, D. V.; Chen, W.-H.; Stannard, A.; Summerfield, A.; Sprafke, J. K.; O’Sullivan, M. C.; Beton, P. H.; Anderson, H. L.; Herz, L. M. Ultrafast 
Delocalization of Excitation in Synthetic Light-Harvesting Nanorings. Chem. Sci. 2015, 6, 181189.

34) Arnold, D. P.; Johnson, A. W.; Mahendran, M. Some Reactions of Meso-

Formyloctaethylporphyrin. J. Chem. Soc., Perkin Trans. 1 1978, 366-370.

35) Crossley, M. J.; Burn, P. L. An Approach to Porphyrin-Based Molecular Wires: Synthesis of a Bis(porphyrin)tetraone and its Conversion to a Linearly Conjugated Tetrakisporphyrin System. J. Chem. Soc., Chem. Commun. 1991, 1569-1571.

36) Anderson, H. L. Conjugated Porphyrin Ladders. Inorg. Chem. 1994 3, 972-981.

37) Lin, V. S.-Y.; DiMagno, S. G.; Therien, M. J. Highly Conjugated Acetylenyl Bridged Porphyrins: New Models for Light-Harvesting Antenna Systems. Science 1994, 264, 1105-1111.

38) Taylor, P. N.; Huuskonen, J.; Rumbles, G.; Aplin, R.T.; Williams, E.; Anderson, H. L. Conjugated Porphyrin Oligomers from Monomer to Hexamer. Chem. Commun. 1998, 909-910.

39) Anderson, H. L. Building Molecular Wires from the Colours of Life: Conjugated Porphyrin Oligomers. Chem. Commun. 1999, 2323-2331.

40) Hoffmann, M.; Wilson, C. J.; Odell, B.; Anderson, H. L. Template-Directed Synthesis of a $\pi$-Conjugated Porphyrin Nanoring. Angew. Chem. Int. Ed. 2007, 46, 3122-3125.

41) Hoffmann, M.; Kärnbratt, J.; Chang, M.-H.; Herz, L. M.; Albinsson, B.; Anderson, H. L. Enhanced $\pi$-Conjugation around a Porphyrin[6] Nanoring. Angew. Chem. Int. Ed. 2008, 47, 4993-4996. 
42) Sprafke, J. K.; Kondratuk, D. V.; Wykes, M.; Thompson, A. L.; Hoffmann, M.;

Drevinskas, R.; Chen, W.-H.; Yong, C. K.; Kärnbratt, J.; Bullock, J. E.; Malfois, M.;

Wasielewski, M. R.; Albinsson, B.; Herz, L. M.; Zigmantas, D.; Beljonne, D.; Anderson, H. L.,

Belt-Shaped $\pi$-Systems: Relating Geometry to Electronic Structure in a Six-Porphyrin Nanoring.

J. Am. Chem. Soc. 2011, 133, 17262-17273.

43) Hogben, H. J.; Sprafke, J. K.; Hoffmann, M.; Pawlicki, M.; Anderson, H. L., Stepwise Effective Molarities in Porphyrin Oligomer Complexes: Preorganization Results in Exceptionally Strong Chelate Cooperativity. J. Am. Chem. Soc. 2011, 133, 20962-20969.

44) Liu, P.; Neuhaus, P.; Kondratuk, D. V.; Balaban, T. S.; Anderson, H. L. CyclodextrinTemplated Porphyrin Nanorings. Angew. Chem. Int. Ed. 2014, 53, 7770-7773.

45) Liu, P.; Hisamune, Y.; Peeks, M. D.; Odell, B.; Gong, J. Q.; Herz, L. M.; Anderson, H. L., Synthesis of Five-Porphyrin Nanorings by using Ferrocene and Corannulene Templates. Angew. Chem. Int. Ed. 2016, 55, 8358-8362.

46) O’Sullivan, M. C.; Sprafke, J. K.; Kondratuk, D. V.; Rinfray, C.; Claridge, T. D. W.; Saywell, A.; Blunt, M. O.; O’Shea, J. N.; Beton, P. H.; Malfois, M.; Anderson, H. L. Vernier Templating and Synthesis of a 12-Porphyrin Nano-Ring. Nature 2011, 469, 72-75.

47) Rickhaus, M.; Vargas Jentzsch, A.; Tejerina, L.; Grübner, I.; Jirasek, M.; Claridge, T. D. W.; Anderson, H. L. Single-Acetylene Linked Porphyrin Nanorings. J. Am. Chem. Soc. 2017, $139,16502-16505$.

48) Lindsey, J. S. Self-Assembly in Synthetic Routes to Molecular Devices. Biological Principles and Chemical Perspectives: A Review. New J. Chem. 1991, 15, 153-180. 
49) Petruska, J. A.; Hodge, A. J. A Subunit Model for the Tropocollagen Macromolecule. Proc. Natl. Acad. Sci. U.S.A. 1964, 51, 871-876.

50) Kelly, T. R.; Xie, R. L.; Weinreb, C. K.; Bregant, T. A Molecular Vernier. Tetrahedron Lett. 1998, 39, 3675-3678.

51) Hunter, C. A.; Tomas, S. Accurate Length Control of Supramolecular Oligomerization: Vernier Assemblies. J. Am. Chem. Soc. 2006, 128, 8975-8979.

52) Wei, T.; Jung, J. H.; Scott, T. F. Dynamic Covalent Assembly of Peptoid-Based Ladder Oligomers by Vernier Templating. J. Am. Chem. Soc. 2015, 137, 16196-16202.

53) Greschner, A. A.; Bujold, K. E.; Sleiman, H. F. Controlled Growth of DNA Structures from Repeating Units using the Vernier Mechanism. Biomacromolecules 2014, 15, 3002-3008.

54) Li, X.; Hao, C.; Tian, C.; Wang, P.; Mao, C. Vernier Assembly: Controlling DNA Polymerization via Length Mismatching. Chem. Commun. 2014, 50, 6361-6363.

55) Kondratuk, D. V.; Sprafke, J. K.; O’Sullivan, M. C.; Perdigao, L. M. A.; Saywell, A.;

Malfois, M.; O’Shea, J. N.; Beton, P. H.; Thompson, A. L.; Anderson, H. L. Vernier-Templated Synthesis, Crystal Structure, and Supramolecular Chemistry of a 12-Porphyrin Nanoring. Chem. Eur. J. 2014, 20, 12826-12834.

56) Kondratuk, D. V.; Perdigao, L. M. A.; O'Sullivan, M. C.; Svatek, S.; Smith, G.; O'Shea, J. N.; Beton, P. H.; Anderson, H. L. Two Vernier-Templated Routes to a 24-Porphyrin Nanoring. Angew. Chem. Int. Ed. 2012, 51, 6696-6699. 
57) Kondratuk, D. V.; Perdigão, L. M. A.; Esmail, A. M. S.; O’Shea, J. N.; Beton, P. H.; Anderson, H. L. Supramolecular Nesting of Cyclic Polymers. Nat. Chem. 2015, 7, 317-322.

58) Svatek, S. A.; Perdigão, L. M. A.; Stannard, A.; Wieland, M. B.; Kondratuk, D. V.; Anderson, H. L.; O’Shea, J. N.; Beton, P. H. Mechanical Stiffening of Porphyrin Nanorings through Supramolecular Columnar Stacking. Nano Lett. 2013, 13, 3391-3395.

59) Kamonsutthipaijit, N.; Anderson, H. L. Template-Directed Synthesis of Linear Porphyrin Oligomers: Classical, Vernier and Mutual Vernier. Chem. Sci. 2017, 8, 2729-2740.

60) Liu, S.; Kondratuk, D. V.; Rousseaux, S. A. L.; Gil-Ramírez, G.; O’Sullivan, M. C.; Cremers, J.; Claridge, T. D. W.; Anderson, H. L. Caterpillar Track Complexes in TemplateDirected Synthesis and Correlated Molecular Motion. Angew. Chem. Int. Ed. 2015, 54, 53555359.

61) Rousseaux, S. A. L.; Gong, J. Q.; Haver, R.; Odell, B.; Claridge, T. D. W.; Herz, L. M.; Anderson, H. L. Self-Assembly of Russian Doll Concentric Porphyrin Nanorings. J. Am. Chem. Soc. 2015, 137, 12713-12718.

62) Neuhaus, P.; Cnossen, A.; Gong, J. Q.; Herz, L. M.; Anderson, H. L. A Molecular Nanotube with 3D $\pi$-Conjugation. Angew. Chem. Int. Ed. 2015, 54, 7344-7348.

63) Favereau, L.; Cnossen, A.; Kelber, J. B.; Gong, J. Q.; Oetterli, R. M.; Cremers, J.; Herz, L. M.; Anderson, H. L. Six-Coordinate Zinc Porphyrins for Template-Directed Synthesis of SpiroFused Nanorings. J. Am. Chem. Soc. 2015, 137, 14256-14259. 
64) Cremers, J.; Haver, R.; Rickhaus, M.; Gong, J. Q.; Favereau, L.; Peeks, M. D.; Claridge, T.

D. W. Herz, L. M.; Anderson, H. L. Template-Directed Synthesis of a Conjugated Zinc Porphyrin Nanoball. J. Am. Chem. Soc. 2018, 140, 5352-5355.

65) Bols, P. S.; Anderson, H. L. Shadow Mask Templates for Site Selective Metal Exchange in Magnesium Porphyrin Nanorings. Angew. Chem. Int. Ed. 2018, 57, 7874-7877.

66) Anderson, S.; Anderson, H. L.; Sanders, J. K. M. Scavenger Templates: Synthesis and Electrospray Mass Spectrometry of a Linear Porphyrin Octamer. Angew. Chem. Int. Ed. 1992, $31,907-910$.

67) Cnossen, A.; Roche, C.; Anderson, H. L. Scavenger Templates: a Systems Chemistry Approach to the Synthesis of Porphyrin-Based Molecular Wires. Chem. Commun. 2017, 53, 10410-10413.

68) Langton, M. J.; Matichak, J. D.; Thompson, A. L.; Anderson, H. L. Template-Directed Synthesis of $\pi$-Conjugated Porphyrin [2]Rotaxanes and a [4]Catenane Based on a Six-Porphyrin Nanoring. Chem. Sci. 2011, 2, 1897-1901.

69) Jin, Y.; Wang, Q.; Taynton, P.; Zhang, W. Dynamic Covalent Chemistry Approaches Toward Macrocycles, Molecular Cages, and Polymers. Acc. Chem. Res. 2014, 47, 1575-1586.

70) Jyothish, K.; Wang, Q.; Zhang, W. Highly Active Multidentate Alkyne Metathesis Catalysts: Ligand-Activity Relationship and Their Applications in Efficient Synthesis of Porphyrin-Based Aryleneethynylene Polymers. Adv. Synth. Catal. 2012, 354, 2073-2078. 